\title{
Varieties of Thermoluminescent Dosimeters Used in the Personnel Dosimetry Laboratory in Radiation Protection Institute in Ghana
}

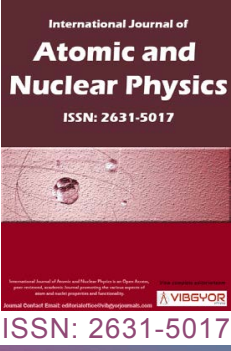

\section{HK Agyeman ${ }^{1 *}$, EO Darko,,2, JK Amoako1,2, J Owusu-Banahene ${ }^{1,2}$, S Inkoom ${ }^{1,2}$, DF

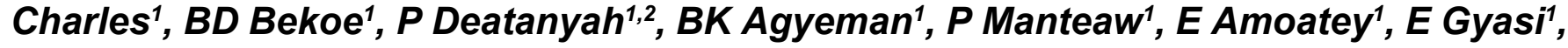 GO Aseidu', P Appiah', EM Abadoo' and G Agyeman'}

\section{${ }^{1}$ Radiation Protection Institute, Ghana Atomic Energy Commission, Ghana}

${ }^{2}$ Graduate School of Nuclear and Allied Sciences, University of Ghana, Atomic Campus, Kwabenya-Accra, Ghana

\begin{abstract}
The four element thermoluminescent dosimeters is normally used to measure doses from whole body such as $\mathrm{Hp}(10.0)$ and $\mathrm{Hp}$ (0.07), extremities and other monitoring services respectively [1]. In this publication, some TLD cards will be identified by using the Harshaw 6600 Plus TLD Reader to obtain the doses that were absorb and some bad dosimeters will be identified as well. This will help in assessing the performance of the good dosimeters that can be used as field cards, or golden cards. Moreover, the good TLD cards will serve as a useful tool in dose assessment and dose evaluation respectively. This study details the distribution and trends of doses among occupationally exposed workers (OEWs) in Ghana during a 5-year period (20112015). The monitored dose data were extracted from the Radiation Protection Institute of the Ghana Atomic Energy Commission's database called the Dose Management System (DMS). The doses of these OEWs analyzed, are divided into four subgroups namely; general radiographers, radiologists, computed tomography (CT) technologists, fluoroscopy technologists. The dose distribution, collective dose and mean annual dose were determined. A total of 1,574 OEWs were monitored comprising of $56 \%$ radiographers, $15 \%$ radiologist, $21 \%$ computed tomography (CT) technologists and $8 \%$ fluoroscopy technologists. The average annual effective dose ranged from 0.36 to $1.70 \mathrm{mSv}$ with radiographers receiving the largest. Fluoroscopy technologist recorded the least annual total collective effective dose value of 0.1 person Sv. The study contributes to the existing works to promote a more comprehensive personal monitoring service for OEWs. Continued analysis of occupational doses should be an integral component of institutional radiation safety programs in Ghana.
\end{abstract}

\section{Keywords}

Single dose chip, Thermo Luminescent Dosimeters (TLD), Occupationally expose workers, Ionizing radiation and dose

*Corresponding author: HK Agyeman, Radiation Protection Institute, Ghana Atomic Energy Commission, PO Box LG 80, Legon-Accra, Ghana

Accepted: March 18, 2020; Published: March 20, 2020

Copyright: (c) 2020 Agyeman HK, et al. This is an open-access article distributed under the terms of the Creative Commons Attribution License, which permits unrestricted use, distribution, and reproduction in any medium, provided the original author and source are credited.

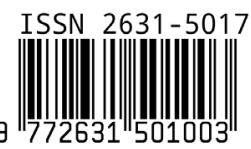

Agyeman et al. Int J At Nucl Phys 2020, 5:018 


\section{Terminology}

TTP: Temperature Time Profile; ABS: Acrylonitrile Butadiene Styrene

\section{Introduction}

In personnel monitoring service, neutron monitoring and environmental monitoring, the use of TLD cards comes in different forms depending on the type of work the Technologist or Radiographer is carried out or performing and the type of radioactive source he is working on. The TLD cards have various parameters such as

1. Single Ring Dosimeters

2. Chest Ring Dosimeters

3. Wrist Dosimeters

4. Multiple element card dosimeters.

Basically, the thermoluminescent consist of a four element doped with $\mathrm{Li}, \mathrm{Mg}$, Ti and $\mathrm{F}$ for measuring doses in personnel monitoring [2]. The heat- ing of the TLD cards result in a glow curve whose area is proportional to the dose.

The Finger ring is made of durable low density polypropylene plastic and is adjustable to fit finger sizes from 16 to $28 \mathrm{~mm}$ in diameter. It is available in a variety of colours to identify different body areas. While the Chest badge is used for estimation of the whole body dose, worn at the chest level. The Wrist badge has strap to be worn around wrist. It is used to estimate the dose to hands and the forearms when they are likely to be selectively exposed [3].

The dosimeters are also produced in certified factories which produced a controlled material quality (Dosimetry) to meet their application purposes.

Some of such factories include is;

1. The ISO 9001 Certified factory [4]. These Certified factories produce the dosimeters in different shapes such as pelletized disks, chips rods micro - cubes.

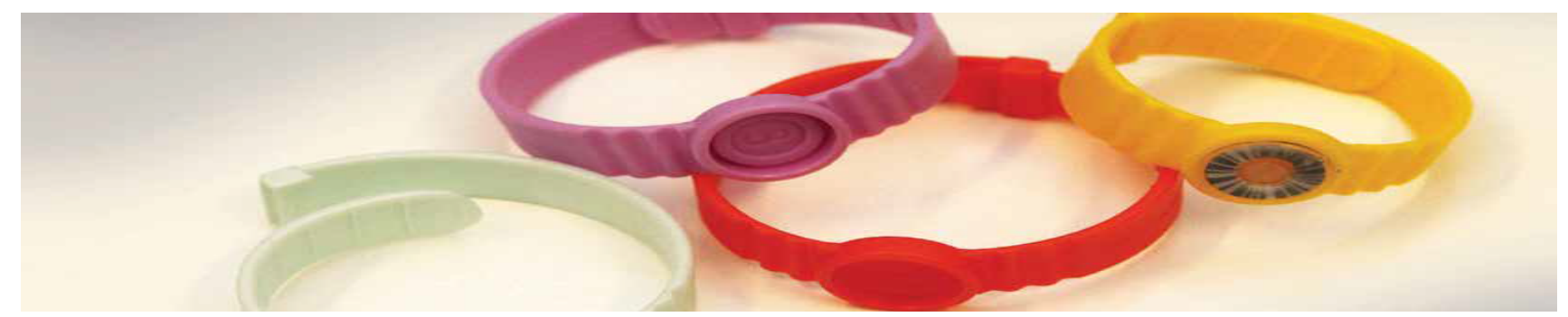

Figure 1a: Picture showing finger ring that are worn by occupationally exposed workers who work with radioactive source.

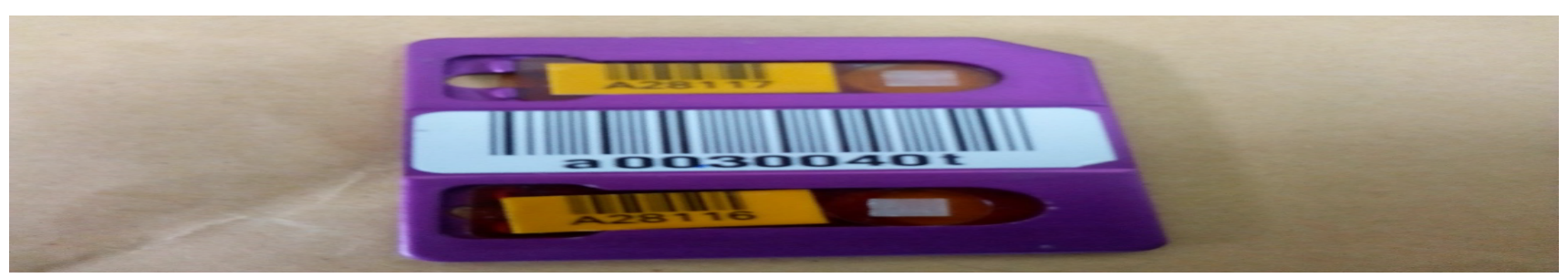

Figure 1b: Showing a picture of a single chip.

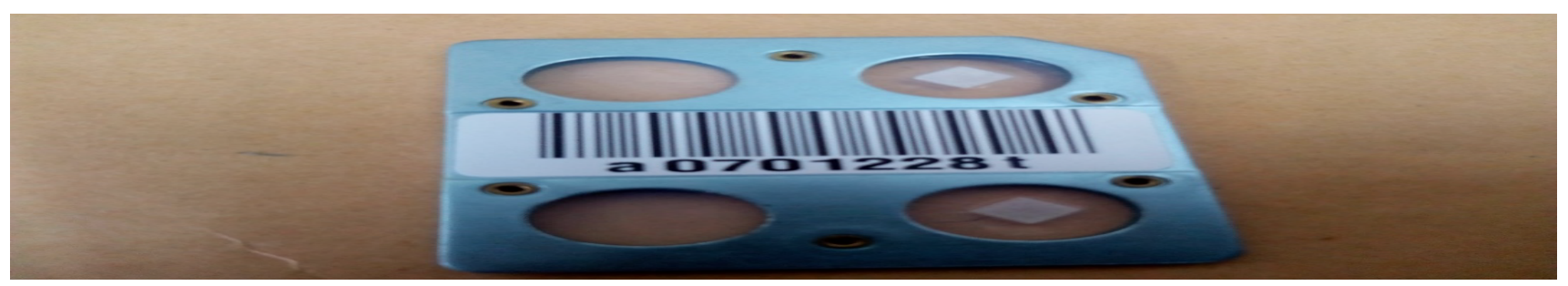

Figure 1c: Showing a picture of a blue TLD Badge. 
2. National Radiation Testing Stations( NRTS).

Showing pictures of Various Colours of TLD Dosimeters (Figure 1a, Figure 1b, Figure 1c, Figure 1d, Figure $1 \mathrm{e}$ and Figure $1 \mathrm{f}$.

\section{TLD Card Holders}

The TLD Card Holders are made up of various colours, which are in-cooperated with filters and they are made up of durable, tissue-equivalent, ABS plastic, and is casketed and sealed to retain the card in a light and moisture excluding environment. The Holder protects the cards from environmental damage and retains the filtration media which attenuate the various radiation types to protect selective entrapment in the TL material. This difference in radiation absorption allows determination of shallow, deep and lens of the eyes doses as well as some energy discrimination.

When the TL material is placed in a holder and sent to the field, when it is placed in the holder, the package is known as thermoluminescent dosimeter.
The purpose of the holder is to serve as a protector. That is it protects the TL material from mechanical damage and crystal damage. Another function of the holder is to allow various filters to be placed in front of the TL crystals. This filters serves as energy dependency which permits the filters to filter out unwanted particles (Figure 2, Figure 3, Figure 4 and Figure 5).

A typical whole body TLD card, shown in Figure 6, has LiF: Ti, Mg thermoluminescent chips (3 $\times 3 \mathrm{~mm}^{2}$ or $\left.1 / 8 \times 1 / 8 \mathrm{in}^{2}\right)$, square, encapsulated between two sheets of Teflon 0.0025 inches (10 $\mathrm{mg} / \mathrm{cm}^{2}$ ) thick and mounted on an aluminium substrate. Three of the chips are fabricated from TLD -700 in either of two thickness: $0.15 \mathrm{~mm}\left(0.006^{\prime \prime}\right)$ or $0.38 \mathrm{~mm}\left(0.015^{\prime \prime}\right)$, and one from TLD - 700 chip, $0.38 \mathrm{~mm}$ thick, covered with $242 \mathrm{mg} / \mathrm{cm}^{2}$ ABS plastic and $91 \mathrm{mg} / \mathrm{cm}^{2} \mathrm{ABS}+893 \mathrm{~A}$ thinner TLD - 700 $\mathrm{mg} / \mathrm{cm}^{3}$ PTFE filters) measures the deep dose. Chip, $0.15 \mathrm{~mm}$ thick $0.06 \mathrm{~mm}$ aluminium Mylar filtration determines the shadow dose. The total filtration for this element, combining the PTFE card encapsulated and the aluminized Mylar filter, is $17 \mathrm{mg} / \mathrm{cm}^{2}$.

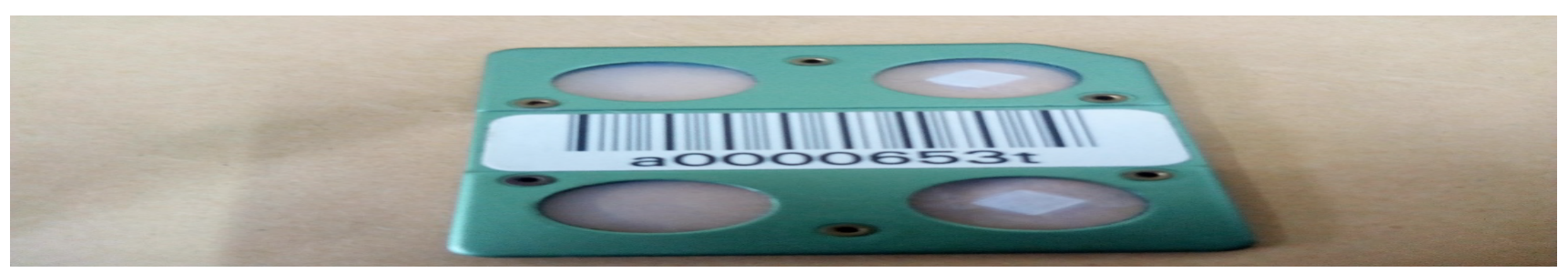

Figure 1d: Showing a picture of a green TLD Badge.

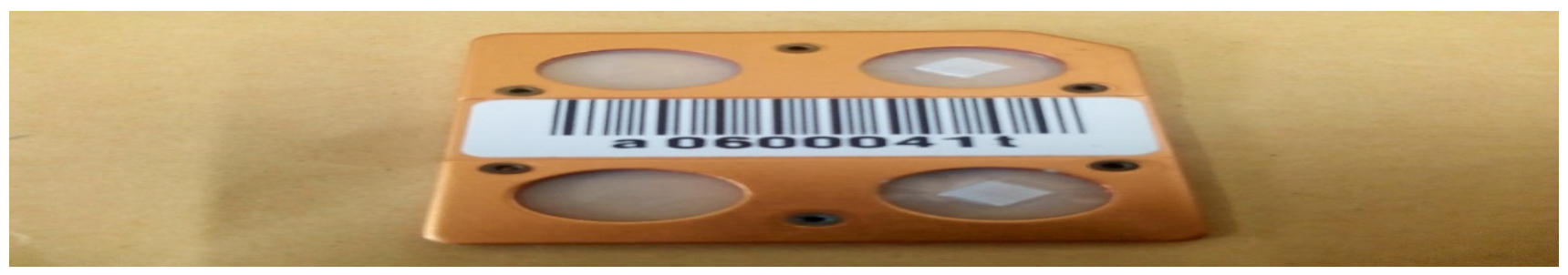

Figure 1e: Showing a picture of a copper TLD Badge.

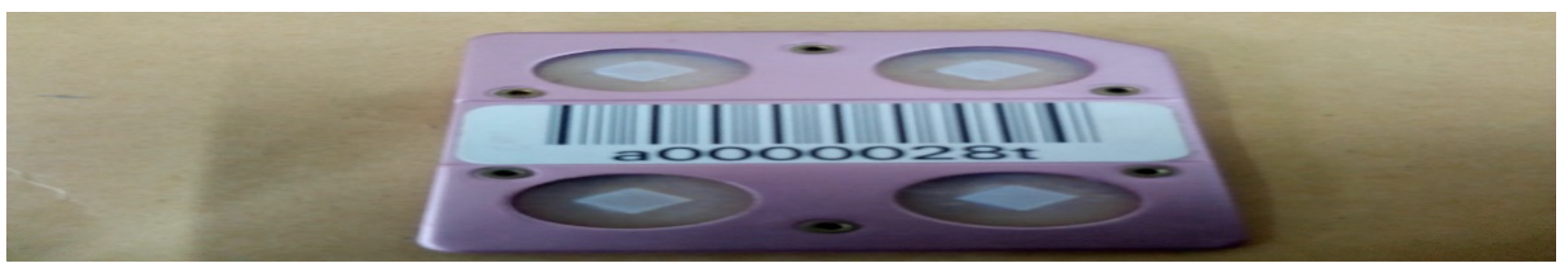

Figure 1f: Showing a picture of a peach TLD Badge. 


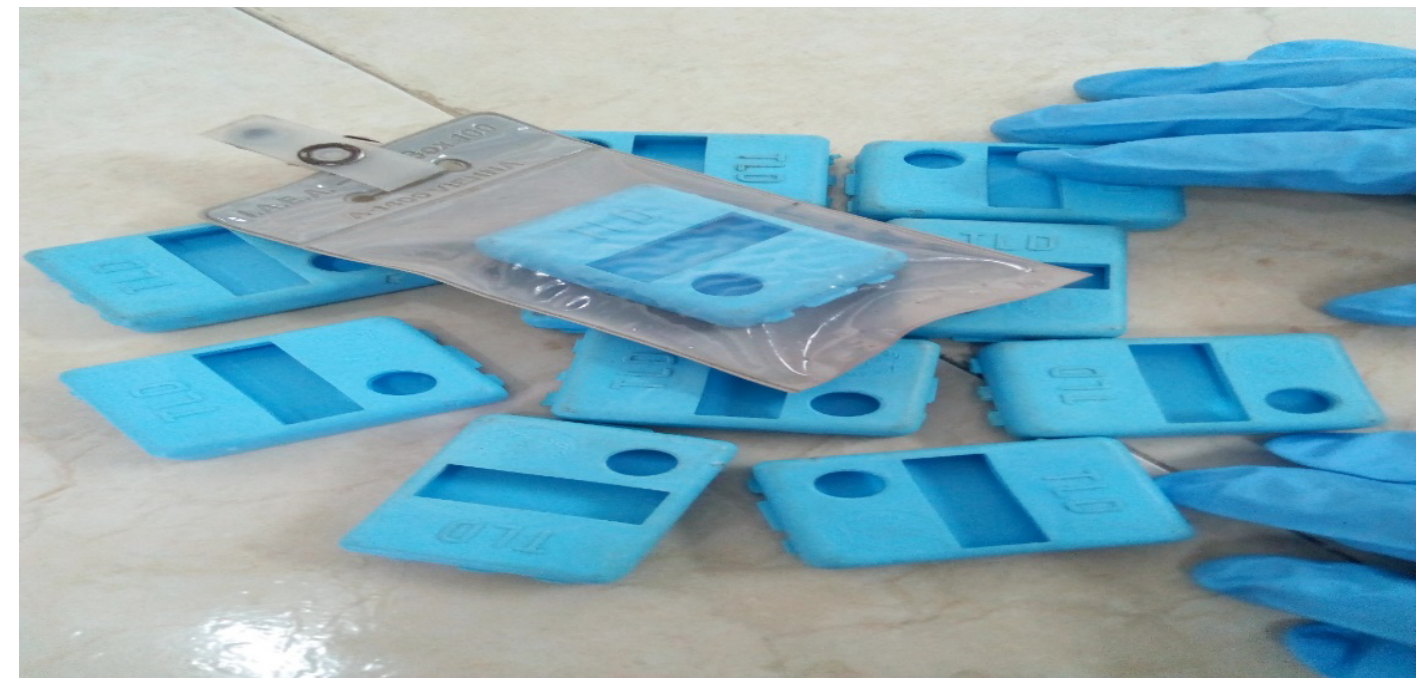

Figure 2: Showing pictures of BLUE TLD holder's covers.

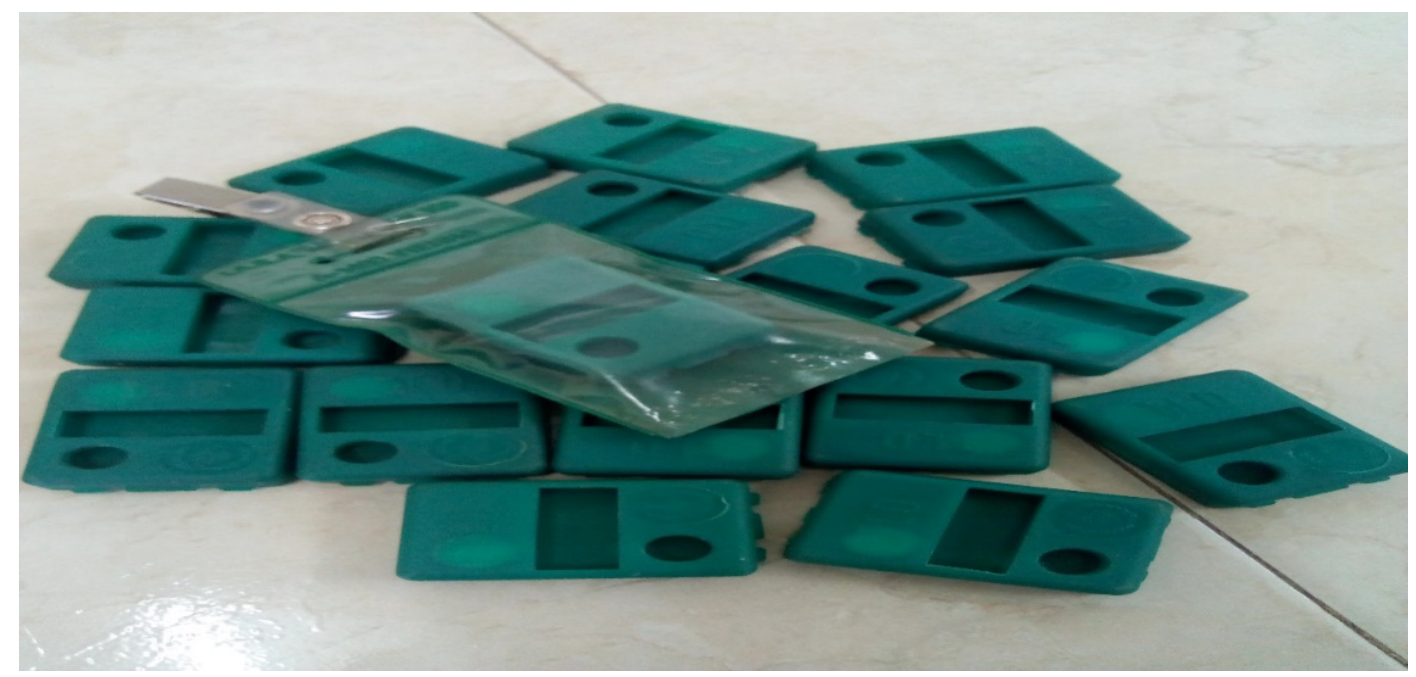

Figure 3: Showing pictures of GREEN TLD holder's covers.

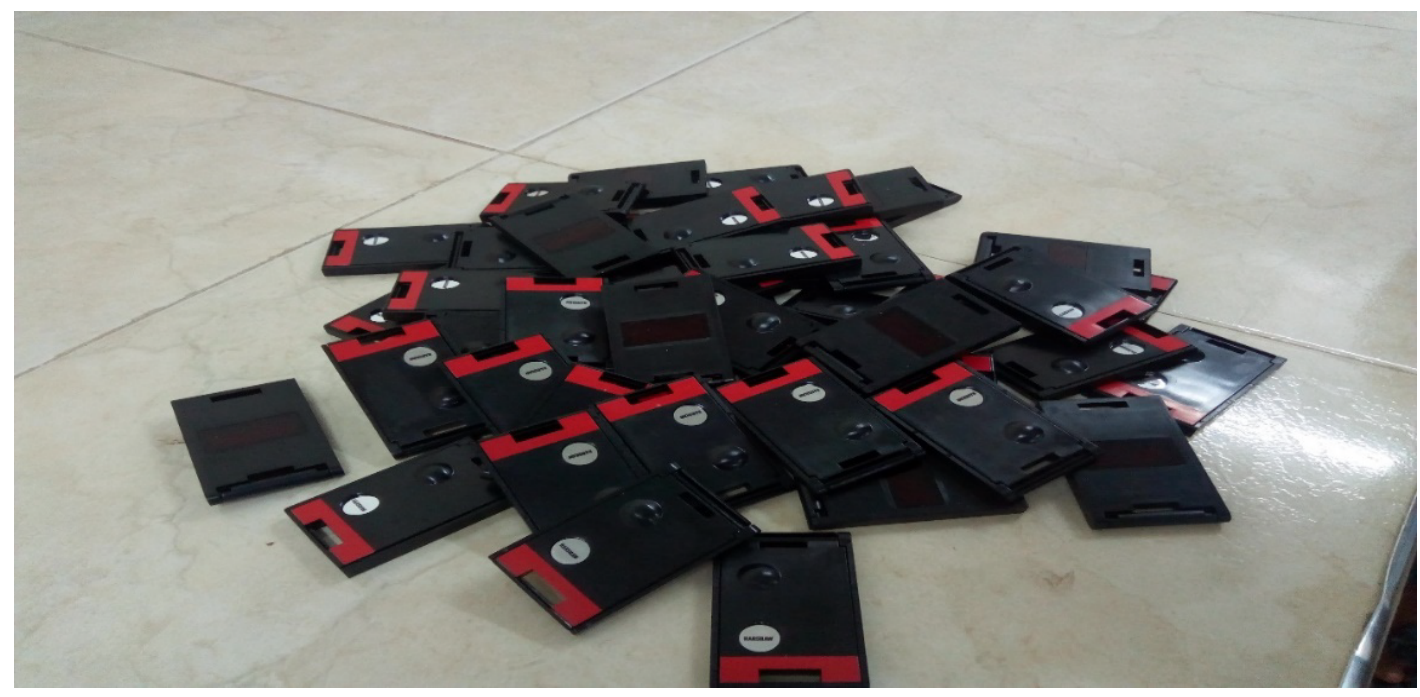

Figure 4: Showing pictures of BLACK TLD holder's covers. 


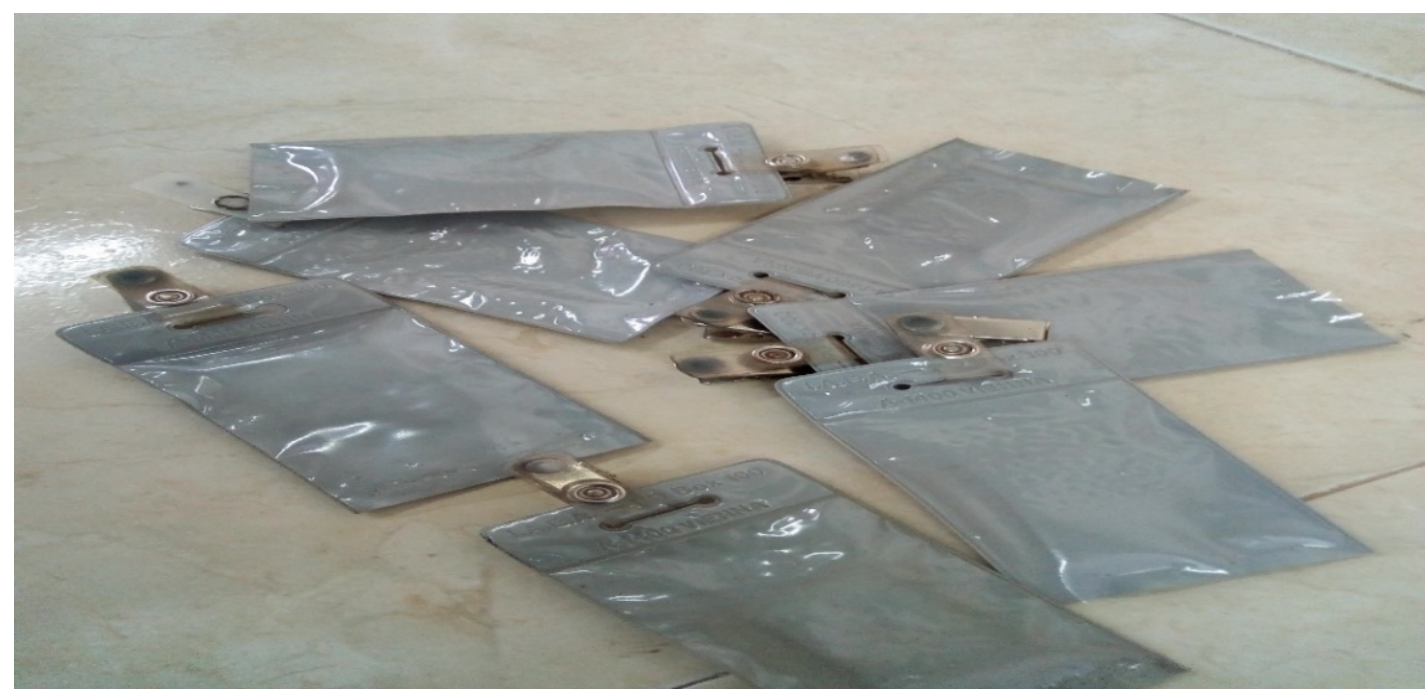

Figure 5: Showing covers of GREY TLD holder's.

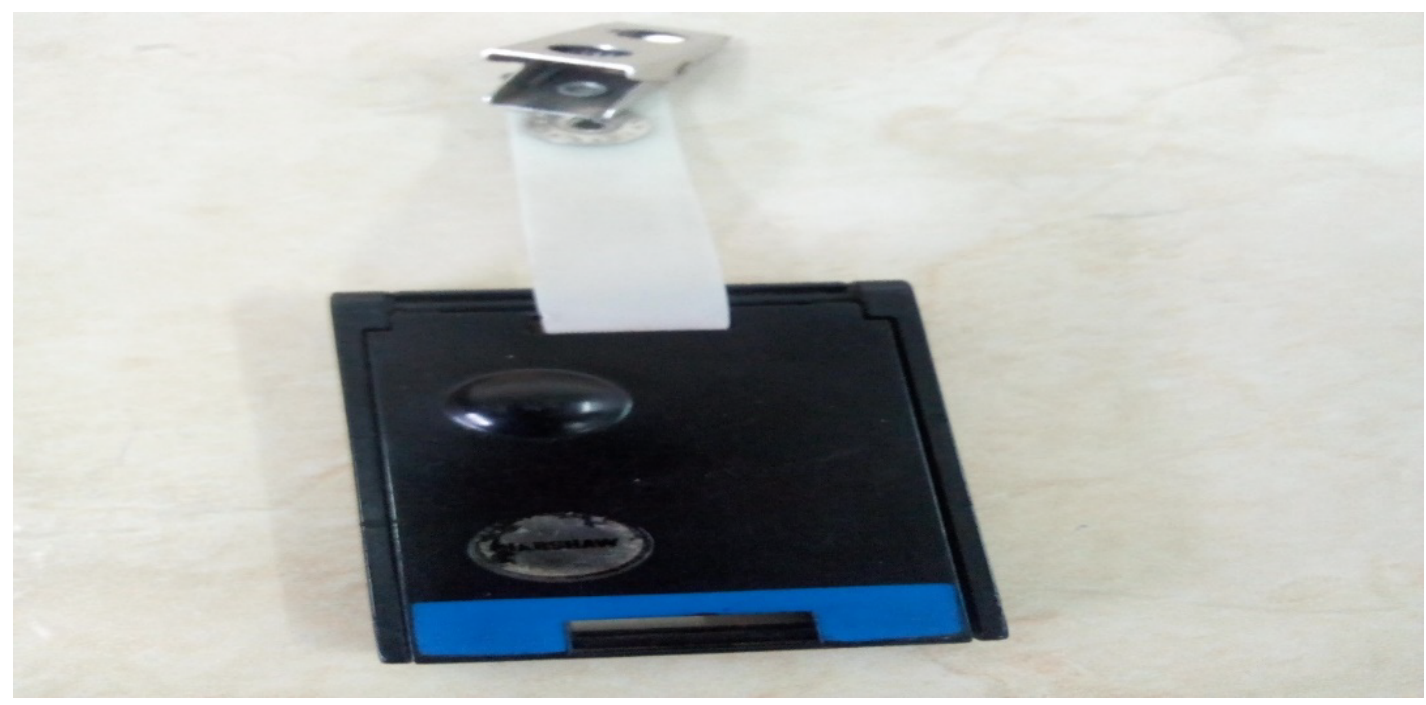

Figure 6: Showing a picture of a typical TLD card encapsulated in TLD card holder.

A TLD - 600 chip, $0.38 \mathrm{~mm}$ thick, with $300 \mathrm{mg} / \mathrm{cm}^{2}$ $A B S$ plastic filtration measures lens of the eye and neutron dose.

The principle is based on the phenomenon of thermos luminescence, the emission of light when certain materials are heated after exposure to radiations. It gives very reliable results since no fading is observed under extreme climatic conditions such ambient temperature and humidity.

Personnel doses, received by Occupationally Exposed Workers are determined from measurement made from the Thermoluminescent Dosimeters which was worn by the Occupationally Exposed Workers respectively. This type of monitoring is known as Personnel Monitoring.

\section{Who Should Use}

The TLD badges to be used only by persons as approved by Radiation Protection Institute directly working with radiation sources such as X-ray units, radioisotopes etc. The dark room technicians, sweepers security guards etc. need not normally be provide with. In case of doubt kindly write to Radiation Protection Institute.

It may be noted that TLD badge is used to measure the radiation dose to which the user is exposed. It does not protect the user from the radiation.

Precaution Measures Needed When Using the TLD Dosimeters 
Table 1: Format of the dosimeters calibration report.

\section{Dosimeter Calibration Report}

\section{Calibration results}

\begin{tabular}{|l|l|l|l|l|l|l|l|}
\hline Date & Time & TTP & Dosimeter ID & (I) & (II) & (III) & (V) \\
\hline $10 / 8 / 2018$ & $10: 50: 28$ & 1 & 701241 & 1.035 & 1.569 & \\
\hline $10 / 8 / 2018$ & $10: 51: 36$ & 1 & 701120 & 1.033 & 1.666 & \\
\hline $10 / 8 / 2018$ & $10: 52: 45$ & 1 & 700989 & 0.9768 & 1.635 & \\
\hline $10 / 8 / 2018$ & $10: 54: 02$ & 1 & 700378 & 0.9805 & 1.721 & \\
\hline $10 / 8 / 2018$ & $10: 55: 31$ & 1 & $* 0700816$ & 1.031 & 1.031 & \\
\hline $10 / 8 / 2018$ & $10: 56: 47$ & 1 & 701164 & 0.9290 & 1.452 & \\
\hline $10 / 8 / 2018$ & $10: 58: 05$ & 1 & 701123 & 0.9733 & 1.485 & \\
\hline $10 / 8 / 2018$ & $10: 59: 36$ & 1 & $* 0700704$ & 0.9520 & 1.467 & \\
\hline $10 / 8 / 2018$ & $11: 00: 53$ & 1 & 701088 & 1.037 & 1.615 & \\
\hline $10 / 8 / 2018$ & $11: 02: 13$ & 1 & 701228 & 1.094 & 1.675 & \\
\hline $10 / 8 / 2018$ & $11: 05: 52$ & 1 & $* 0701085$ & 0.9442 & 1.463 & \\
\hline $10 / 8 / 2018$ & $11: 07: 17$ & 1 & 700429 & 0.9243 & 1.677 & \\
\hline $10 / 8 / 2018$ & $11: 08: 36$ & 1 & 700644 & 1.070 & 1.675 & \\
\hline $10 / 8 / 2018$ & $11: 10: 05$ & 1 & 700397 & 1.025 & 1.541 & \\
\hline $10 / 8 / 2018$ & $11: 11: 34$ & 1 & $* 0700965$ & 0.9493 & 1.583 & \\
\hline $10 / 8 / 2018$ & $11: 12: 57$ & 1 & 700050 & 0.7810 & 1.281 & \\
\hline $10 / 8 / 2018$ & $11: 14: 31$ & 1 & 701104 & 0.9527 & 1.464 & \\
\hline $10 / 8 / 2018$ & $11: 15: 55$ & 1 & 700056 & 0.9372 & 1.541 & \\
\hline $10 / 8 / 2018$ & $11: 17: 25$ & 1 & 700898 & 0.9435 & 1.609 & \\
\hline $10 / 8 / 2018$ & $11: 18: 51$ & 1 & 700867 & 0.9365 & 1.589 & \\
\hline $10 / 8 / 2018$ & $11: 23: 01$ & 1 & 701122 & 0.9351 & 1.626 & \\
\hline & & & & & \\
\hline
\end{tabular}

The Dosimeters ID with exteres ( $\left(^{*}\right)$ were identified as BAD DOSIMETERS [5,6]. These include: Dosimeter ID *0700818, ${ }^{*} 0700704,{ }^{*} 0701085$ and ${ }^{*} 0700965$.

- Do not share your TLD Dosimeter with anyone.

- Always leave your TLD Dosimeter badge in the control room when not in use.

- Do not bring your TLD Dosimeter badge near radiation source (Table 1) [5,6].

\section{Where to Wear the TLD Dosimeters}

In special cases, depending upon the nature of radiation work, if the doses to hands and forearms are expected to significantly higher than at the chest level, additional wrist badges may be procedure and used [7]. Examples of such categories are persons handling radioisotopes from close distances and radiologists/doctors doing the special investigations such as cardiac catheterization, angiography's etc.
One TLD badge should be worn compulsorily at the chest level. If a lead rubber apron is used, (for example": In diagnostic X-ray departments) TLD badge should be worn under the lead apron at the chest level.

The dose recorded by the TLD badge worn at chest level represents the whole body dose equivalent.

Persons who working with industrial radiography cameras should compulsorily use wrist badges in addition to chest badges [8].

\section{Preparation of Reports (OEW'S)}

Choose any Clients (Occupationally Exposed Work's) that have been monitored to the History forms. 
Select the Worksheet to make sure that all entries have been made correctly.

Use the Dose Management System (DMS) to prepare the Client Report and send a copy to the various Personnel (The Manager - The Deputy - Director - The Director) for verification, clarification and endorsement.

Post the OEW'S report either by EMS or DHL.

A complete annual report can be prepared from the OEW'S Clients (each person) badge can be used respectively.

Mostly, a report is prepared and file as a permanent record for each of the OEW'S been monitored and this is kept in the OEW'S Client folder respectively.

\section{References}

1. Colgan PA, Currivan L, Fenton D (2008) An assessment of annual whole-body occupational radiation exposure in Ireland. Radiat Prot Dosim 1: 12-20.

2. Glasgow GP, Eichling J, Yoder RC (1906) Observations on personnel dosimetry for radiotherapy personnel operating high-energy LINACS. Health Physics 50: 789-795.

3. Hasford F, Owusu B, Amoako JK, Otoo F, Darko EO, et al. (2011) Assessment of annual whole-body occupational radiation exposure in medical practice in ghana. Radiat Prot Dosim 149: 431-437.

4. Larsson L, Katz R (1976) Supralinearity of thermoluminescent dosimeters. Nuclear Instrumentation and Methods 138: 631-636.

5. Miller A, McLaughlin WL (1982) Calculation of the energy dependence of dosimeters response to ionizing photons. The International Journal of Applied Radiation and Isotopes 33: 1299-1310.

6. (2002) Occupational radiation protection. Radiation protection and safety guide, GRPB-G3:2000.

7. Ranogajec-Komor M (2003) Thermoluminescencedosimetry - application in environmental monitoring. Radiation Safety Management 2: 2-16.

8. Shani G (2001) Radiation dosimetry: Instrumentation and methods. ( $2^{\text {nd }}$ edn), CRC Press, USA. 